\title{
Renal Proliferative and Phenotypic Changes in Rats With Two-Kidney, One-Clip Goldblatt Hypertension
}

Eudora Eng, Murielle Veniant, Jürgen Floege, Jürgen Fingerle, Charles E. Alpers, Joel Menard, Jean-Paul Clozel, and Richard J. Johnson

Angiotensin II (AII) is a vasoconstrictive peptide with hypertrophic and mitogenic effects on many cell types. Previous studies have shown that in vivo administration of AII in rats results in proliferation of, and phenotypic changes in, many renal cell populations, but in doses also causing hypertension. Thus, it was not possible to differentiate nonhemodynamic from hypertensive effects of AII. Therefore, we studied rats with renin-dependent, AII-mediated hypertension (the two-kidney, oneclip Goldblatt model; mean systolic blood pressure $238 \pm 48 v 140 \pm 6 \mathrm{~mm} \mathrm{Hg}$ in sham-operated controls). The unclipped kidneys, which were exposed to high blood pressure, developed significant glomerular and tubulointerstitial injury, tubulointerstitial cell proliferation, dense focal interstitial monocyte-macrophage influx, increased deposition of types I and IV collagen, as well as increased cellular expression of desmin and actin, in tubulointerstitial areas when examined at 11 weeks. In contrast, clipped kidneys, protected from hypertension but with high local renin expression, had minimal abnormalities. These studies suggest that in this model increased renin, and presumably AII, does not mediate significant proliferative or phenotypic changes in the kidney in the absence of hypertension at 11 weeks. Am J Hypertens 1994; 7:177-185

KEY WORDS: Angiotensin II, Goldblatt hypertension, rat, kidney.

\section{$\mathrm{A}$} ngiotensin II (AII) mediates hypertension by several mechanisms, including direct vasoconstriction, aldosterone stimulation, sodium retention, ${ }^{1}$ and increased sympathetic activity. ${ }^{2}$ Interestingly, prolonged or repeated administration of AII in rats may also lead to sustained hypertension despite later withdrawal of the

Received January 25, 1993. Accepted October 19, 1993.

From the Division of Nephrology, Department of Medicine, and the Department of Pathology, University of Washington, Seattle, Washington; Institut National de la Santé et de la Recherche Medicale, Paris, France; and F. Hoffmann-LaRoche, Basel, Switzerland. This work was supported by U.S. Public Health Service grants DK43422 and DK02142.

Address correspondence and reprint requests to Eudora Eng, MD, Division of Nephrology, Mailstop RM-11, University of Washington, Seattle, WA 98195.
AII. ${ }^{3}$ The mechanism by which this occurs is not known, but one possibility is that AII-mediated hypertension may result from structural changes within the kidney. Studies performed more than 50 years ago in the renin-dependent model of renovascular hypertension (ie, the two-kidney, one-clip Goldblatt model), demonstrated that significant vascular, glomerular, and tubulointerstitial injury occur in the hypertensive (ie, unclipped) kidney.,5 Once histologic injury was induced, removal of the clip was usually ineffective in restoring blood pressure to normal. ${ }^{5}$

Recently we examined the kidneys of normal rats that had received pressor doses of exogenous AII for 14 days. ${ }^{6}$ Routine light microscopy revealed only minor and focal tubulointerstitial changes, but by immunostaining marked phenotypic and proliferative changes were documented in various renal cell pop- 
ulations. Particularly impressive were changes in the tubulointerstitium, including a proliferation of distal tubule and collecting duct cells, proliferation and phenotypic modulation of renal interstitial cells with expression of $\alpha$-smooth muscle actin, an interstitial monocyte-macrophage infiltration, and interstitial fibrosis with type IV collagen deposition.

In these in vivo studies, it was not possible to distinguish pressor from nonpressor effects of AII. In vitro experiments, however, have provided ample evidence of the direct hypertrophic or mitogenic effects of AII on many cell types. ${ }^{7-10}$ In addition, indirect evidence also suggests that AII may mediate vascular smooth muscle cell proliferation in vivo independent of hypertension. ${ }^{11}$

To attempt to dissociate the hypertensive effects of AII from a nonhemodynamic action, we examined the kidneys from rats with renin- and AII-dependent renovascular hypertension (the two-kidney, one-clip Goldblatt model), a model in which the unclipped kidney is exposed to elevated renin and AII levels and high blood pressure, whereas the clipped kidney is exposed to only increased renin and AII without hypertension. In addition to routine histology, we examined tissue from both clipped and unclipped kidneys by immunohistochemistry for evidence of cell proliferation, phenotypic changes in cytoskeletal proteins, infiltrating leukocyte populations, and extracellular matrix deposition. Significant histologic injury was found in the unclipped, hypertensive kidney, with tubular and interstitial cell proliferation, interstitial cell phenotypic changes in cytoskeletal proteins, and an infiltration of macrophages into the interstitium. In contrast, minimal changes were noted in the "protected," clipped kidney. This suggests that AII, in the absence of hypertension, may have only a minor role in mediating the proliferative and phenotypic changes in the kidney at 11 weeks in this model.

\section{MATERIALS AND METHODS}

Experimental Protocol Normotensive male Wistar rats (Füllinsdorf, Switzerland) weighing 250 to $350 \mathrm{~g}$ were used. At 8 weeks of age, under barbiturate anesthesia (sodium hexobarbital, Bayer, Frankfurt, Germany), the left renal artery was stenosed with a silver clip (slit width $0.2 \mathrm{~mm}$ ). The right renal artery was left intact. Six rats serving as control underwent a sham operation that consisted of the same surgical manipulation but without placement of the clip. All animals had free access to water and were fed standard rat chow. Weekly systolic blood pressures were measured in conscious, unrestrained rats by tail cuff plethysmography in both groups from 6 to 11 weeks after surgery when animals were killed and renal tis- sue obtained. Blood pressures are reported as the mean of systolic blood pressures measured during the last 5 weeks before death.

Inclusion Criteria Rats that underwent clip placement were evaluated 6 weeks after surgery. Only those rats with systolic blood pressure (SBP) $>180$ $\mathrm{mm} \mathrm{Hg}$ were included for further study. Twelve rats from 16 operated met these criteria. In addition, rats with necrotic kidneys secondary to clips placed too tightly were considered to no longer represent an AIImediated state and were excluded. Four of the 12 rats failed to meet this criterion and were eliminated from further evaluation.

Histology Tissue was fixed in methyl Carony's solution, embedded in paraffin, and processed as previously described. ${ }^{12}$ Four-micrometer sections were stained with the periodic acid-Schiff reagent and counterstained with hematoxylin. Additional $4-\mu \mathrm{m}$ sections were stained using an indirect avidin-biotin immunoperoxidase technique ${ }^{12}$ with the following primary antibodies: F37.2D12, a murine monoclonal antibody to human renin ${ }^{13}$ (gift of M. Laprade, Sanofi Recherche, Montpellier, France); 19A2, a murine immunoglobulin $\mathrm{M}(\operatorname{IgM})$ monoclonal antibody against the human proliferating cell nuclear antigen (PCNA)/ cyclin (Coulter Corp., Hileah, FL) ${ }^{14}$; ED-1 (Bioproducts for Science, Indianapolis, IN), a murine monoclonal IgG to a cytoplasmic antigen present in monocyte-macrophages and dendritic cells ${ }^{15}$; RP-3, a murine monoclonal IgM against rat neutrophils (gift of F. Sendo, Yamagata, Japan) ${ }^{16}$; OX-22 (Accurate Chemical and Scientific Crop., Westbury, NY), a murine monoclonal $\mathrm{IgG}_{1}$ against the high molecular weight form of the common leukocyte antigen present on rat $B$ and some T cells; anti- $\alpha$-sm- 1 , a murine monoclonal $\mathrm{IgG}_{2}$ directed against $\alpha$-smooth muscle actin (gift of G. Gabbiani, Geneva, Switzerland) ${ }^{17}$; D33 (Dako Corp., Carpenteria, CA), a murine monoclonal $\mathrm{IgG}_{1}$ to desmin; a polyclonal goat antihuman, antibovine type IV collagen antibody (Southern Biotech, Birmingham, AL); and an IgG fraction of polyclonal guinea pig antirat type I collagen (gift of L. Iruela-Arispe and H. Sage, Seattle, WA). All of these antibodies cross-react with the respective rat antigens.

Tissue sections were also double immunostained for both proliferating (PCNA +) cells and monocytemacrophages (ED + cells) as previously described. ${ }^{18}$ The tissue was scored as described ${ }^{19}$ : cells were identified as proliferating monocyte-macrophages if they showed positive nuclear PCNA staining and the nucleus was completely surrounded by ED-1-positive cytoplasm; proliferating cells with PCNA-positive nuclei not bordering on ED-1-positive cytoplasm were 
classified as not being monocyte-macrophages; and PCNA-positive cells that could not be unequivocally identified as ED-1 positive or negative (ie, ED-1 + cytoplasm did not completely surround the PCNA + nucleus) were considered nonclassifiable. Negative controls included omission of either of the primary antibodies that resulted in no double staining.

Quantitation of Cell Proliferation and Macrophage Involvement A semiquantitative estimate of renal renin content was obtained by determining the percent of glomerular cross sections (at least 36 glomeruli per biopsy counted) with juxtaglomerular immunostaining for renin, as previously reported. ${ }^{6}$

The mean number of proliferating (PCNA + ) cells and monocyte-macrophages (ED-1+) per glomerulus was determined by enumerating the total number of positive cells in 50 consecutive glomerular cross sections per biopsy. Only glomeruli with at least 20 capillary loops were evaluated.

Cytoskeletal Changes The smooth muscleassociated actin isoform, $\alpha$-smooth muscle actin, is not expressed by normal rat mesangial cells in vivo, but is expressed by mesangial cells in rats with AIImediated hypertension. ${ }^{6}$ We, therefore, evaluated the mesangial expression of this actin isoform using a scale of 0 to $4+$ as previously described. ${ }^{12}$

Desmin, a muscle-associated intermediate filament protein, is expressed constitutively by mesangial cells with variable expression by visceral epithelial cells in normal rat glomeruli. ${ }^{12}$ However, expression of desmin by glomerular visceral epithelial cells is also increased in rats made hypertensive by chronic infusion of AII. ${ }^{6} \mathrm{We}$, therefore, examined the expression of desmin as it relates to glomerular epithelial cell locations (ie, in the periphery of the glomerular tuft) using the following semiquantitative scale: 0 , no staining; $1+$, light staining of visceral epithelial cells; $2+$, moderate staining of all epithelial cells, or strong staining in up to one-third; $3+$, strong staining in one- to two-thirds of epithelial cells; $4+$, strong staining in greater than two-thirds of cells examined.

Tissue Renin In addition to immunostaining biopsies for renin, tissue renin from sham, clipped, and unclipped kidneys was assayed. Half of each longitudinally sectioned kidney was frozen. After thawing, renin was extracted as previously described. ${ }^{20}$ Tissue renin activity was measured by radioimmunoassay of angiotensin I generated by incubation with an excess of rat renin substrate.

Statistics Data are expressed as mean \pm SD. Comparison between groups (sham, clipped, or unclipped) was made using the one-way analysis of variance (ANOVA) with modified $t$ tests using the
Bonferroni correction. Statistical significance was defined as $P<.05$.

\section{RESULTS}

Characterization of the Disease Rats underwent placement of a clip on one renal artery and were evaluated at 6 weeks for development of hypertension. Four of the 12 rats found to be hypertensive (SBP $\geq 180 \mathrm{~mm} \mathrm{Hg}$ ) had necrotic clipped kidneys and, therefore, were excluded from the study. Mean SBP for the last 5 weeks of the study in the remaining eight rats (238 $\pm 48 \mathrm{~mm} \mathrm{Hg})$ was significantly higher than in control, sham-operated rats $(140 \pm 6 \mathrm{~mm} \mathrm{Hg})$.

In the early phases of hypertension in the twokidney, one-clip model renin is increased in the hypoperfused (clipped), and suppressed in the hypertensive (unclipped), kidney. ${ }^{21}$ To confirm that this process was operative in our rats, the juxtaglomerular renin content at 11 weeks was assessed in both clipped and unclipped kidneys using a monoclonal antibody to renin (Figure 1), and tissue renin levels were calculated for clipped, unclipped, and control kidneys. These results are summarized in Table 1 and demonstrate that renin production was significantly


FIGURE 1. Representative juxtaglomerular renin staining in unclipped (a) and clipped (b) kidneys of rats with Goldblatt hypertension. Renin staining in clipped kidneys occasionally extended from the afferent arteriole into the glomerulus $(\times 630)$. 
TABLE 1. ASSESSMENT OF TISSUE RENIN

\begin{tabular}{lcc}
\hline Kidney & $\begin{array}{c}\text { Immunostaining for } \\
\text { Juxtaglomerular Renin }\end{array}$ & $\begin{array}{c}\text { Tissue Renin } \\
\text { (ng AI/h/g tissue) }\end{array}$ \\
\hline $\begin{array}{c}\text { Sham } \\
(\mathrm{n}=6)\end{array}$ & $26.8 \%( \pm 11.3)$ & $470.0( \pm 187.3)$ \\
$\begin{array}{c}\text { Clipped } \\
(\mathrm{n}=8)\end{array}$ & $47.3 \%( \pm 6.1) \dagger$ & $1506.6( \pm 790.1)^{\pi}$ \\
$\begin{array}{c}\text { Unclipped } \\
(\mathrm{n}=8)\end{array}$ & $8.9 \%( \pm 7.9) \ddagger$ & $86.4( \pm 76.7)^{* *}$ \\
\hline
\end{tabular}

$A I$, angiotensin $I$. $S D$

$t \mathrm{P}<.001$ compared with sham.

$\ddagger \mathrm{P}<.001$ compared with sham and clipped.

${ }^{\mathrm{P}} \mathrm{P}<.05$ compared with sham.

$* * \mathrm{P}<.05$ compared with sham and clipped.

elevated in clipped kidneys compared with sham, but significantly suppressed in unclipped kidneys. Taken together, these data strongly suggest an AII-driven state.

By light microscopy (periodic acid-Schiff stain), glomeruli of unclipped hypertensive kidneys were often hyalinized and occasionally had areas of focal segmental glomerulosclerosis (Figure 2). Microaneurysms and intraluminal thrombi were rarely present, although dilated glomerular capillary loops were common in most specimens. Bowman's capsule was thickened and frequently surrounded by mild periglomerular fibrosis in rats with higher mean SBPs. Synechiae were seen infrequently. Tubulointerstitial changes included tubular dilatation ranging in degree from mildly increased luminal diameter to massively dilated tubules with almost complete effacement of the tubular cells. Almost all biopsies of unclipped kidneys contained dilated tubules, although biopsies

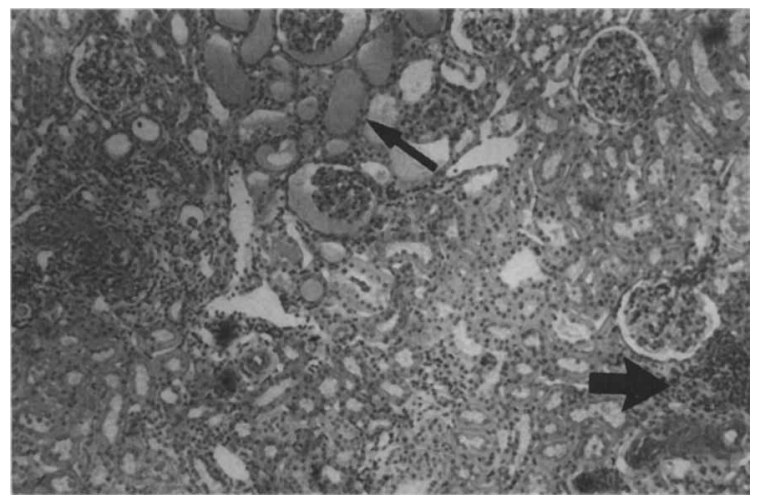

FIGURE 2. Periodic acid-Schiff stain of an unclipped kidney of a hypertensive (mean SBP $>200 \mathrm{~mm} \mathrm{Hg}$ ) Goldblatt rat showing tubular dilatation and formation (narrow arrow), and dense focal interstitial infiltrates of mononuclear cells (wide arrow) $(\times 100)$. demonstrating the most dilated tubules and tubular casts were seen in rats with the most severe hypertension ( $\mathrm{SBP} \geq 200 \mathrm{~mm} \mathrm{Hg}$ ). In addition, dense focal interstitial mononuclear cellular infiltrates were noted, especially in areas of tubular damage, in rats with severe hypertension. Tubular architecture in the regions of infiltrating cells was often disrupted. In contrast, rats with less severe hypertension (SBP $<200 \mathrm{mg} \mathrm{Hg}$ ) had only mild interstitial infiltrates.

Glomeruli from clipped kidneys appeared normal by light microscopy. Occasional low-grade mononuclear cellular infiltrates were seen in interstitial areas. With the exception of one kidney, no tubular dilation, disruption, or casts were seen.

Proliferation Cell proliferation was quantitated by immunostaining tissue sections for PCNA, a nuclear protein that is increased from late $G_{1}$ to the $M$ phase of the cell cycle. ${ }^{22}$ The number of glomerular PCNA + cells did not significantly differ in sham animals $(0.33$ $\pm 0.08)$ compared with clipped rats $(0.24 \pm 0.16)$, although a mild, but significant, increase in the number of PCNA + glomerular cells was noted in the unclipped kidneys $(0.81 \pm 0.43, P<.05$ compared with sham and clipped kidneys). In contrast, a dramatic increase in PCNA + cells was seen in the tubulointerstitium of unclipped hypertensive kidneys, compared with both clipped and control (Figure 3). Because both tubular and interstitial cell proliferation occurred focally, quantitation was difficult. Although occasional tubules had one or two proliferating cells, other primarily distal tubules were seen in which almost every cell was PCNA + . In the interstitium, mononuclear PCNA + cells were also clustered, frequently in zones of injury. Although more tubular cell proliferation was seen in clipped kidneys compared with sham-operated control kidneys, the proliferation was relatively minor and never included entire cross sections of PCNA-positive tubules. Foci of PCNA + interstitial mononuclear cells were also increased in clipped kidneys, but never as large as the dense areas in the unclipped kidneys.

Leukocyte Infiltration To determine what population of cells constituted the dense interstitial infiltrates seen predominantly in the unclipped kidneys, tissues were stained with specific antibodies to monocyte-macrophages and dendritic cells (ED-1), neutrophils (RP-3), and lymphocytes (OX-22). Glomerular monocyte-macrophage counts were similar in sham (1.99 \pm 0.69$)$, unclipped (1.42 \pm 0.79$)$, and clipped $(1.06 \pm 0.55)$ kidneys. However, unclipped kidneys stained heavily and focally with ED-1 in damaged tubulointerstitial regions (Figure 4). All biopsies were uniformly negative for RP-3. Lymphocytes were 

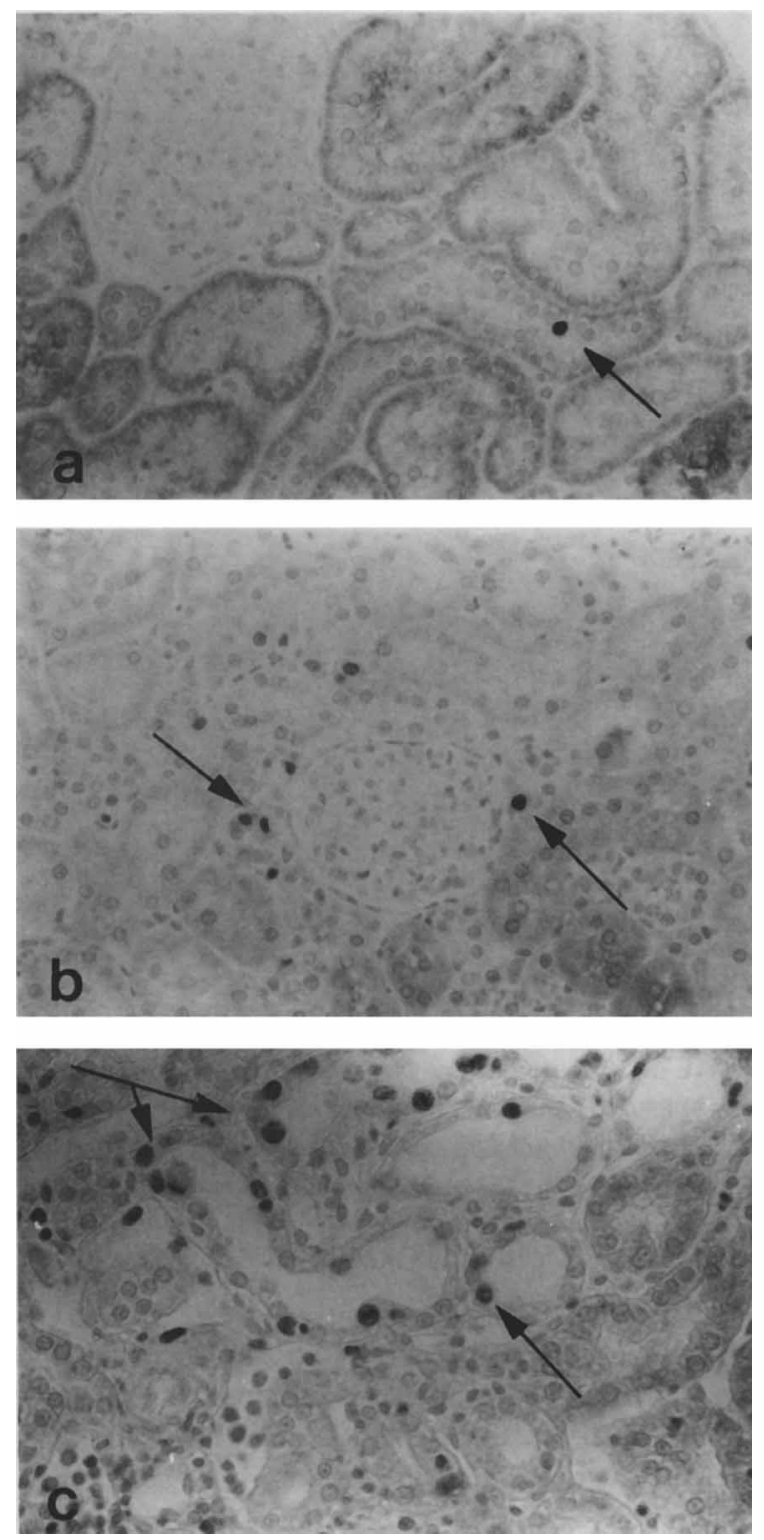

FIGURE 3. Immunostaining for the proliferating nuclear cell antigen (PCNA) (arrow) in sham control kidneys (a) shows only rare positive cells. Tubules and interstitium of clipped kidneys (b) have occasional PCNA + cells, whereas frequent areas of damage in unclipped kidneys (c) have many PCNA+ tubular cells $(\times 400)$.

noted in rare dense focal groups in the unclipped, but not clipped, kidneys in interstitial locations.

To determine whether monocyte-macrophages were the proliferating interstitial cells, tissue was double immunostained for ED-1 and PCNA. Only $8.6 \%$ of PCNA + cells were double labeled. However, because ED-1 may not label all monocytemacrophage populations, it is possible that some proliferating monocyte-macrophages may not have been recognized.
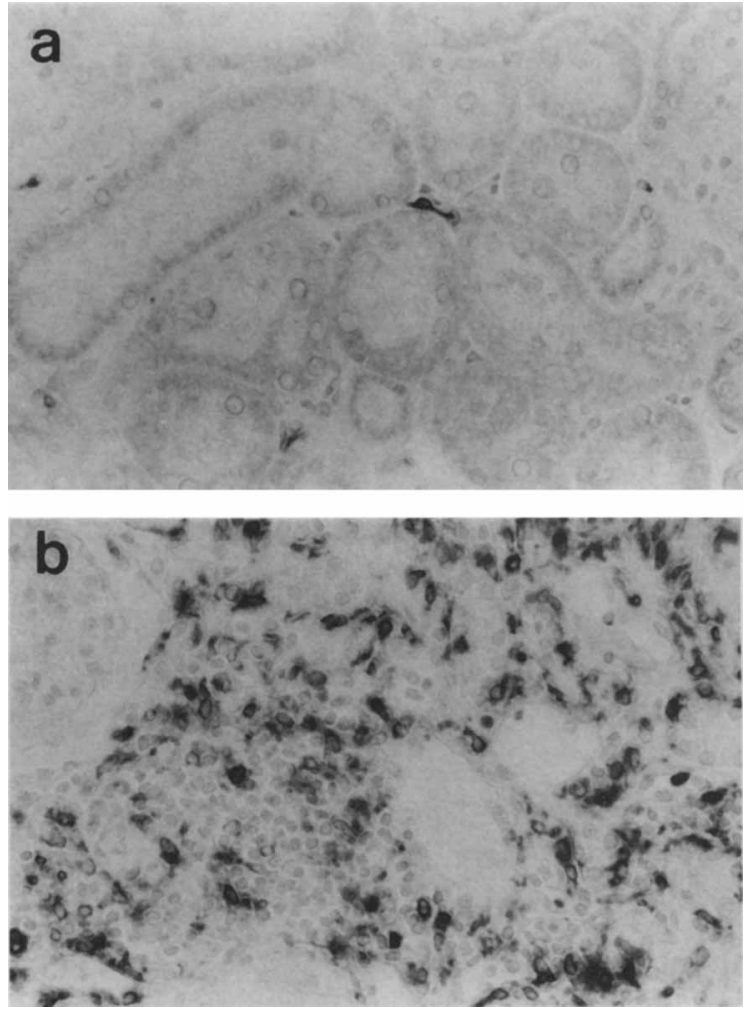

FIGURE 4. Interstitial monocyte-macrophages are occasionally seen in clipped kidneys of Goldblatt rats (a) and sham controls, but dense foci are present only in unclipped kidneys (b), especially in areas of tubular damage $(\times 400)$.

Cytoskeletal Changes Desmin is expressed normally by mesangial cells and the staining in mesangial regions in both clipped and unclipped kidneys was similar to that seen in control animals. However, when evaluated using a semiquantitative score, desmin staining in glomerular visceral epithelial cells was mildly increased in clipped kidneys $(0.86 \pm 0.29)$ compared with sham controls $(0.60 \pm 0.45, P<.05)$, but markedly increased in unclipped, hypertensive kidneys $(2.16 \pm 0.49, P<.05$ compared with sham and clipped kidneys) (Figure 5). Desmin was also expressed by cells in the interstitium in areas of tubular injury within the unclipped kidneys. In contrast, $\alpha$-smooth muscle actin was not expressed to any significant degree within glomeruli of clipped or unclipped kidneys (mean glomerular actin score $0.28 \pm$ 0.23 in unclipped $v 0.12 \pm 0.09$ in clipped kidneys, and $0.13 \pm 0.03$ in sham kidneys). However, staining for this actin isoform was markedly increased in a population of mesenchymal cells in areas of tubulointerstitial damage in a manner similar to desmin (Figure 6).

Fibrosis Staining for types I and IV collagen was comparable in the kidneys of control animals and the 

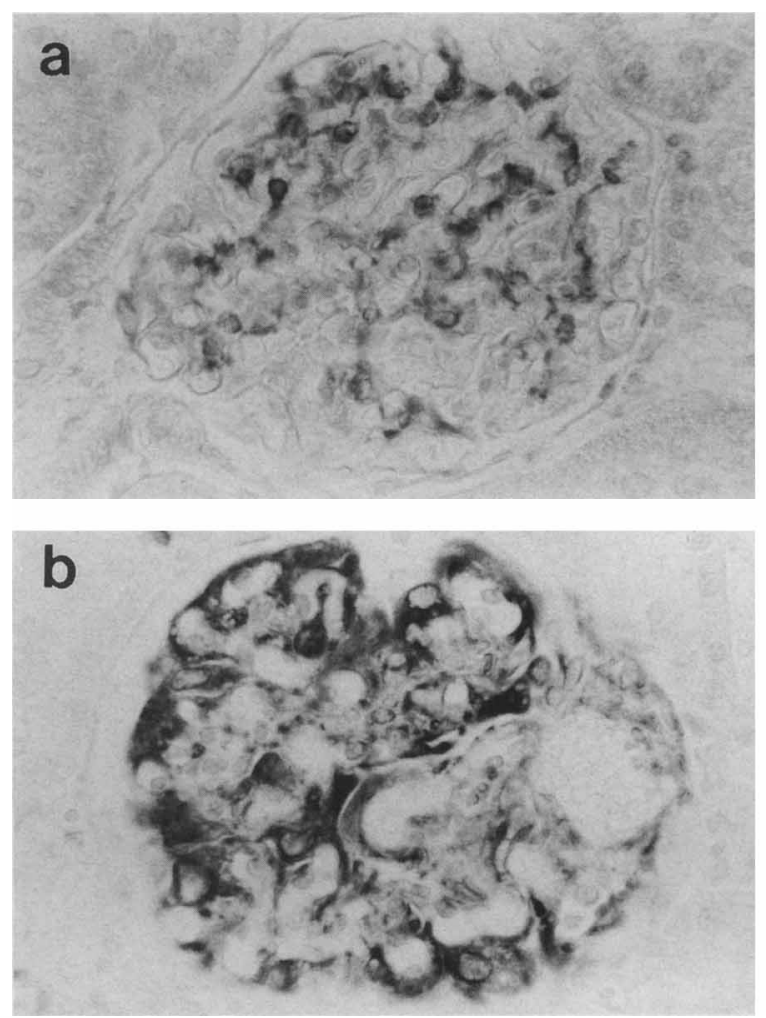

FIGURE 5. Glomerular desmin staining in predominantly mesangial regions in clipped kidneys (a) is similar to that seen in sham controls. Staining for desmin in unclipped kidneys (b) is markedly increased, especially in epithelial cell locations $(\times 630)$.

clipped kidneys of Goldblatt rats, and was seen in periglomerular, tubular, and vascular (types I and IV) and intraglomerular (type IV) areas. However, a dramatic increase of these collagens was noted in the interstitium in areas of tubular injury in unclipped kidneys (Figure 7).

\section{DISCUSSION}

Recent studies have shown that short-term continuous infusion of AII rats results in renal cell proliferation and phenotypic changes. ${ }^{6}$ In doses causing hypertension, AII induced tubular and interstitial cell proliferation, de novo mesangial cell and interstitial cell expression of the vascular smooth muscleassociated actin isoform, $\alpha$-smooth muscle actin, and upregulation of the intermediate filament protein, desmin, by glomerular visceral epithelial cells.

It could not be determined from these previous studies whether the proliferative and phenotypic changes resulted from hypertension caused by AII or from nonhemodynamic effects of AII. Elevated blood pressure has been reported to have trophic ${ }^{23,24}$ or mitogenic ${ }^{11,25}$ effects on vascular smooth muscle cells. Crane and Dutta ${ }^{26}$ have demonstrated similar mito-
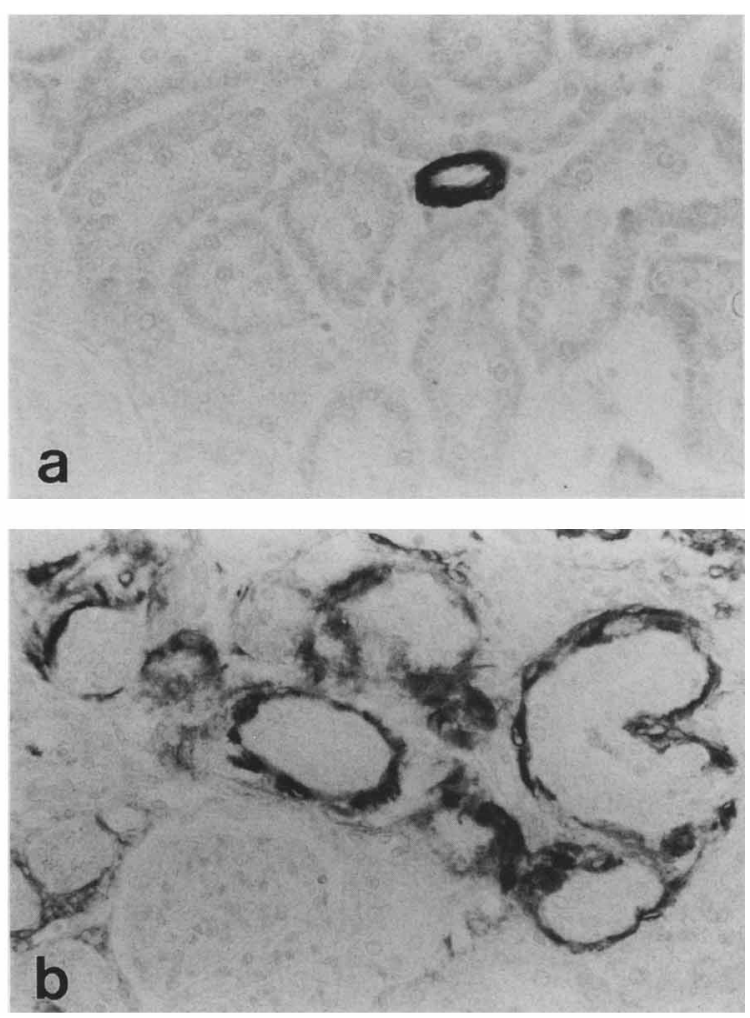

FIGURE 6. Staining for $\alpha$-smooth muscle actin is positive only in blood vessels of sham or clipped kidneys (a), but is dramatically increased in unclipped kidneys (b). Expression of this actin isoform represents a phenotypic change and is seen in focal areas of unclipped, but not clipped, kidneys. A similar tubulointerstitial staining pattern is seen for desmin $(\times 400)$.

genic effects on glomerular and tubular cells in rats with AII-independent deoxycorticosterone acetate (DOCA) salt-induced hypertension. In addition, indirect evidence for the proliferative effects of hypertension has been provided by studies in both AIIdependent and independent models of hypertension in which administration of various classes of antihypertensive drugs prevented rise in both systemic blood pressure and vascular smooth muscle cell DNA synthesis. ${ }^{11}$ Indeed, it has been suggested that DNA synthesis in these cells correlates with the rate of the rise, rather than the peak, of blood pressure. ${ }^{27}$

However, AII itself has been reported to be mitogenic for a variety of cells in culture under certain conditions. In vitro studies have demonstrated proliferative effects of AII on human neonate and juvenile aortic smooth muscle cells, ${ }^{28}$ and human fetal ${ }^{10}$ an transformed murine ${ }^{29}$ mesangial cells. Evidence for the mitogenic role of AII in vivo has also been provided by studies showing inhibition of vascular smooth muscle cell proliferation after balloon catheter injury in rats treated with a specific AII receptor antagonist. ${ }^{30}$ 

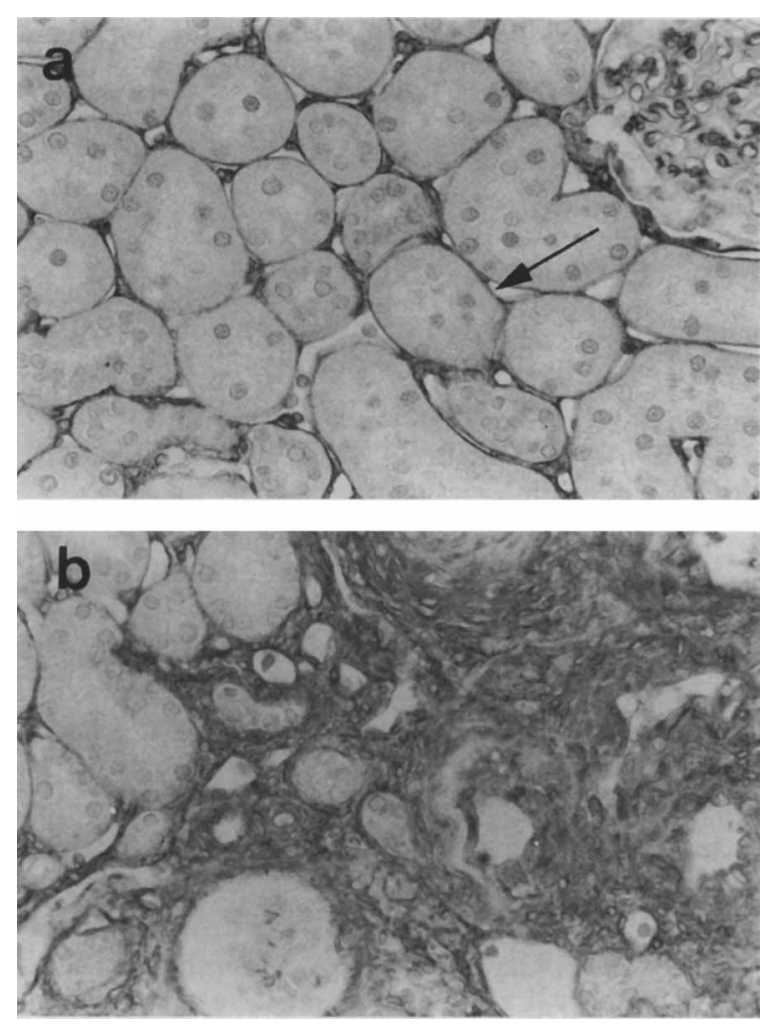

FIGURE 7. Immunostaining for collagen type IV (arrow) in clipped kidneys (a) and sham controls is seen in the tubular basement membrane, but is markedly increased in areas of tubulointerstitial damage and fibrosis in unclipped kidneys (b) $(\times 400)$.

We, therefore, attempted to separate the hemodynamic from nonhemodynamic effects of AII on renal cell proliferation and phenotypic changes by studying the two-kidney, one-clip Goldblatt model in rats in which circulating renin and AII levels are known to be elevated and in which one kidney (ie, the unclipped kidney) is exposed to systemic pressures, whereas the other, clipped kidney is effectively protected. Although we did not measure AII levels, it is known that renal tissue levels of AII are elevated in both clipped and unclipped kidneys at 7 and 25 days. ${ }^{31}$ Therefore, the evidence that our model was AII dependent is indirect, but it is suggested by the immunostaining for renin, as well as tissue renin levels, both of which are significantly increased in the clipped kidney, but suppressed in the unclipped kidney.

In our study, dramatic tubular and interstitial cell proliferation was seen primarily in the unclipped, hypertensive kidney. A small increase in tubular cell proliferation was seen in the clipped, nonhypertensive kidneys, and is consistent with the mild stimulatory effect of AII on other cell types. ${ }^{10,28,29}$ This mitogenic effect could be mediated by the AII receptors shown to reside on tubular cells, ${ }^{32}$ and is in contrast to in vitro findings that have shown no mitogenic effects of AII on murine proximal tubular cells. ${ }^{8} \mathrm{Al}-$ though our results do not rule out a potentiating role for AII, as has been shown with epidermal growth factor on cultured proximal tubular cells, ${ }^{9,33}$ the dramatic increase in tubular cell proliferation seen only in unprotected kidneys suggests that it is mainly through its hemodynamic effects that AII mediates proliferation.

These results are at variance with those of Cantin et $\mathrm{al}^{34}$ who also examined proliferative changes in an AII-mediated model of hypertension induced by partial ligation of the aorta between the two renal arteries. Examination of the left, nonhypertensive kidney revealed little glomerular cell proliferation, but marked proliferation of inner cortical (and to a lesser extent, medullary) tubules as detected by autoradiography. However, their kidneys were ischemic and showed marked atrophy. In contrast, we excluded kidneys with apparent evidence of ischemia or atrophy, in the belief that this would be a confounding variable.

Similar to the tubular and interstitial cell proliferative changes, increased glomerular visceral epithelial cell desmin expression, the only dramatic glomerular finding in our study, was likewise upregulated primarily in the unprotected kidney, whereas its expression in mesangial cells was unchanged in all three groups. Although normally a marker for musclederived cells, desmin has been shown to be variably present in glomeruli visceral epithelial cells, ${ }^{12,35,36}$ and to be increased in these cells in several different experimental models of glomerulonephritis. ${ }^{37}$ The observation that increased desmin expression in glomerular epithelial cells occurred primarily in the unclipped, but not clipped, kidneys emphasizes the importance of the hypertensive effects of AII. Indeed, one might postulate that desmin expression in the glomerular epithelial cell marks an adaptive response to the epithelial cells to increased glomerular pressure or stretch-mediated shape changes induced by glomerular hypertension. Although desmin expression in glomerular epithelial cells was increased in both the present and previous study, ${ }^{6}$ glomerular $\alpha$-smooth muscle actin expression was not increased in our model. It is possible, however, that such glomerular phenotypic modulation, unlike that seen in the tubulointerstitium, occurred early and resolved before biopsy at 11 weeks.

Traditionally, the majority of interstitial cells in the renal cortex and outer medulla have been thought to be fibroblasts, ${ }^{38}$ but in at least two models of renal injury they have been shown to express smooth muscle-associated proteins. ${ }^{6,39}$ The finding of de novo expression of the muscle-related proteins desmin and $\alpha$-smooth muscle actin by interstitial cells in un- 
clipped kidneys in this study may represent transition of these cells to a myofibroblast state, as has been suggested for renal interstitial cells in animals infused with AII. ${ }^{6}$ Interstitial fibroblasts have been shown recently to express the $\beta$-subunit of the platelet-derived growth factor receptor. ${ }^{40}$ This suggests a mechanism by which activated interstitial fibroblasts may be stimulated to proliferate, which could lead to increased collagen production and eventual fibrosis.

Angiotensin II has been demonstrated to increase the expression of collagen type I in culture murine mesangial, and collagen type IV in murine proximal tubular, cells in vitro. ${ }^{9,29}$ However, in vivo, the importance of the pressor effects of AII are further underscored by the increased expression of types I and IV collagen in the renal interstitium in hypertensive, but not protected, kidneys. Such changes of fibrosis were also reported in rats made hypertensive by AII infusion. ${ }^{6}$ In both models of AII-mediated hypertension, kidneys exposed to high pressures were also infiltrated by monocyte-macrophages, which is of interest as macrophages are known to express a large number of vasoactive substances, cytokines, and growth factors, ${ }^{41}$ including platelet-derived growth factor, basic fibroblast growth factor, and transforming growth factor- $\beta$. These cytokines might then act directly or in concert with AII to stimulate tubular and interstitial cells to proliferate or produce extracellular matrix.

These data are consistent with the hypothesis that the hemodynamic effects of AII are necessary for the tubular and interstitial cell proliferative and phenotypic changes in this experimental model. We recognize that it is possible that the hemodynamic manipulations may also affect other regulatory or counterregulatory factors that could confound the interpretation of the study. Unfortunately, there is no way to separate the hemodynamic from the nonhemodynamic effects of AII without affecting blood flow. However, two important findings emerge from this study. First, significant tubulointerstitial injury occurs in the unclipped hypertensive kidneys, with tubular cell proliferation, interstitial cell proliferation and phenotype change, macrophage infiltration, and collagen deposition. This is important given previous observations that tubular and interstitial injury is critical in the progression to renal failure in a variety of renal diseases. ${ }^{42-45}$ Second, despite very high levels of tissue renin (and probably AII), the clipped kidneys were morphologically normal and had minimal proliferative or phenotypic changes in the interstitium. Therefore, this study suggests that in this model of injury, AII in the absence of hypertension has only minimal effect in the initiation and progression of the tubulointerstitial changes characteristic of chronic renal injury.

\section{ACKNOWLEDGMENTS}

The authors thank Dr. William Couser for his encouragement and advice.

\section{REFERENCES}

1. Hall JE, Guyton AC, Salgado HC, et al: Renal hemodynamics in acute and chronic angiotensin II hypertension. Am J Physiol 1978;235:F174-F179.

2. Zimmerman BG, Sybertz EJ, Wong PC: Interaction between sympathetic and renin-angiotensin system. J Hypertens 1984;2:581-587.

3. Koletsky S, Rivera-Velez JM, Pritchard WH: Production of hypertension and vascular disease by angiotensin. Arch Pathol 1966;82:99-106.

4. Wilson C, Byrom FB, Lond MD: Renal changes in malignant hypertension. Lancet 1939;1:136-139.

5. Wilson C, Byrom FB: The vicious circle in Bright's disease. Experimental evidence from the hypertensive rat. Q J Med 1940;10:65-96.

6. Johnson RJ, Alpers CE, Yoshimura A, et al: Renal injury from angiotensin II mediated hypertension. Hypertension 1992;19:464 474 .

7. Schelling P, Gantin D, Speck G, Fischer H: Effects of angiotensin II and angiotensin II antagonist saralasin on cell growth and renin in 3T3 and SV 3T3 cells. J Cell Physiol 1979;98:503-514.

8. Geisterfer AAT, Peach MJ, Owens GK: Angiotensin II induces hypertrophy, not hyperplasia, of cultured rat aortic smooth muscle cells. Circ Res 1988;62:749-756.

9. Wolf G, Neilson EG: Angiotensin II induces cellular hypertrophy in cultured murine proximal tubular cells. Am J Physiol 1990;259:F768-F777.

10. Ray PE, Aguilera G, Kopp JB, et al: Angiotensin II receptor-mediated proliferation of cultured human fetal mesangial cells. Kidney Int 1991;40:764-771.

11. Loeb AL, Bean BL: Antihypertensive drugs inhibit hypertension-associated aortic DNA synthesis in the rat. Hypertension 1986;8:1135-1142.

12. Johnson RJ, Iida $\mathrm{H}$, Alpers $\mathrm{CE}$, et al: Expression of smooth muscle cell phenotype by rat mesangial cells in immune complex nephritis. J Clin Invest 1991;87: 847-858.

13. Galen FX, Devausx C, Atlas S, et al: New monoclonal antibodies directed against human renin. J Clin Invest 1984;74:723-735.

14. Ogata K, Kurki P, Celis JE, et al: Monoclonal antibodies to a nuclear protein (PCNA/cyclin) associated with DNA replication. Exp Cell Res 1987;168:475-486.

15. Dijkstra CD, Döpp EA, Joling P, Kraal G: The heterogeneity of mononuclear phagocytes in lymphoid organs: distinct macrophages subpopulations in the rat recognized by monoclonal antibodies ED1, ED2 and ED3. Immunology 1985;54:589-599.

16. Sekiya S, Gotoh S, Yamashita T, et al: Selective depletion of rat neutrophils by in vivo administration of a monoclonal antibody. J Leukoc Biol 1989;49:96-102.

17. Skalli O, Ropraz P, Trzeciak A, et al: A monoclonal antibody against $\alpha$-smooth muscle actin: a new probe 
for smooth muscle differentiation. J Cell Biol 1986;103: 2787-2796.

18. Iida $H$, Seifert $R$, Alpers $C E$, et al: Platelet-derived growth factor (PDGF) and PDGF receptor are induced in mesangial proliferative nephritis in the rat. Proc Natl Acad Sci 1991;88:6560-6564.

19. Floege J, Burns MW, Alpers CE, et al: Glomerular cell proliferation and PDGF expression precede glomerulosclerosis in the remnant kidney model. Kidney Int 1992;41:297-309.

20. DeRouffignac C, Bonvalet JP, Menard J: Renin content in superficial and deep glomeruli of normal and salt loaded rats. Am J Physiol 1974;226:150-154.

21. Koletsky S, Pavlicko KM, Rivera-Velez JM: Reninangiotensin activity in hypertensive rats with a single ischemic kidney. Lab Invest 1971;24:41-44.

22. Kurki P, Vanderlaan M, Dolbeare F, et al: Expression of proliferating cell nuclear antigen (PCNA)/cyclin during the cell cycle. Exp Cell Res 1986;166:209-219.

23. Owens GK, Rabinovitch PS, Schwartz SM: Smooth muscle cell hypertrophy versus hyperplasia in hypertension. Proc Natl Acad Sci 1981;78:7759-7763.

24. Owen GK, Schwartz SM: Vascular smooth muscle cell hypertrophy and hyperploidy in the Goldblatt hypertensive rat. Circ Res 1983;53:491-501.

25. Chobanian AV, Lichtenstein AH, Schwartz JH, et al: Effects of deoxycorticosterone/salt hypertension on cell ploidy in rat aortic smooth muscle cells. Circulation 1978;75(suppl 1):102-106.

26. Crane WAJ, Dutta LP: The utilization of tritiated thymidine for deoxyribonucleic acid synthesis by the lesions of experimental hypertension in rats. J Pathol Bacteriol 1963;86:83-97.

27. Carlier PG, Rorive G, Barbason H: Kinetics of proliferation of rat aortic smooth muscle cells in Goldblatt one-kidney, one-clip hypertension. Clin Sci 1983;65: 351-357.

28. Campbell-Boswell M, Robertson AL: Effects of angiotensin II and vasopressin on human smooth muscle cells in vitro. Exp Mol Pathol 1981;35:265-276.

29. Wolf G, Haberstroh U, Neilson EG: Angiotensin II stimulates the proliferation and biosynthesis of type I collagen in cultured murine mesangial cells. Am J Pathol 1992;140:95-107.

30. Prescott MF, Webb RL, Reidy MA: Angiotensinconverting enzyme inhibitor versus angiotensin II AT receptor antagonist: effects on smooth muscle cell migration and proliferation after balloon catheter injury. Am J Pathol 1991;139:1-6.

31. Guan S, Fox J, Mitchell KD, Navar LG: Angiotensin and angiotensin converting enzyme tissue levels in two-kidney, one clip hypertensive rats. Hypertension 1992;20:763-767.

32. Mujais SK, Kauffman S, Katz AL: Angiotensin II binding sites in individual segments of the rat nephron. J Clin Invest 1986;77:315-318.

33. Norman J, Badie-Dezfooley B, Nord EP: EGF-induced mitogenesis in proximal tubular cells: potentiation by angiotensin II. Am J Physiol 1987;253:F299-F309.

34. Cantin M, Araujo-Nascimento M, Benchimol S, Desormeaux Y: Metaplasia of smooth muscle cells into juxtaglomerular cells in the juxtaglomerular apparatus, arteries and arterioles of the ischemic (endocrine) kidney. Am J Pathol 1977;87:581-602.

35. Stamenkovic I, Skalli O, Gabbiani G: Distribution of intermediate filament proteins in normal and diseased human glomeruli. Am J Pathol 1986;125:465-475.

36. Yaoita E, Kawasaki K, Yamamoto T, Kihara I: Variable expression of desmin in rat glomerular epithelial cells. Am J Pathol 1990;136:899-908.

37. Floege J, Alpers CE, Sage EH, et al: Marker of complement-dependent and complement-independent glomerular visceral epithelial cell injury in vivo: expression of anti-adhesive proteins and cytoskeletal changes. Lab Invest 1992;67:486-497.

38. Lemley $\mathrm{KV}$, Kriz $\mathrm{W}$ : Anatomy of the renal interstitium. Kidney Int 1991;39:370-381.

39. Nagle RB, Kneiser MR, Bulger RE, Benditt EP: Induction of smooth muscle characteristics in renal interstitial fibroblasts during obstructive nephropathy. Lab Invest 1973;29:422-427.

40. Alpers CE, Seifert RA, Hudkins KL, et al: PDGFreceptor localizes to mesangial, parietal epithelial and interstitial cells in human and primate kidneys. Kidney Int 1993;43:286-294.

41. Nathan CF: Secretory products of macrophages. J Clin Invest 1987;79:319-326.

42. Risdon RA, Sloper JC, de Wardener HE: Relationship between renal function and histological changes found in renal-biopsy specimens from patients with persistent glomerular nephritis. Lancet 1986;1:363-366.

43. Schainuck LI, Striker GE, Cuttler RE, Benditt EP: Structural-functional correlations in renal disease. Part II: the correlations. Hum Pathol 1970;1:631-641.

44. Striker GE, Schainuck LI, Cutler RE, Benditt EP: Structural-functional correlations in renal disease. Part I: a method for assaying and classifying histopathologic changes in renal disease. Hum Pathol 1970;1:615-630.

45. Bohle A, Mackensen-Haen S, von Gise $H$, et al: The consequences of tubulointerstitial changes for renal function in glomerulopathies: a morphometric and cytological analysis. Pathol Res Pract 1990;186;135-144. 